\title{
PENGEMBANGAN SISTEM INFORMASI GEOGRAFIS BERBASIS MOBILE ANDROID UNTUK STUDI KEBOCORAN JARINGAN PIPA PDAM (Studi Kasus: Sub Zona 109, Kota Surabaya)
}

\author{
DEVELOPMENT OF ANDROID MOBILE BASED GEOGRAPHIC INFORMATION SYSTEM \\ FOR PDAM PIPELINE NETWORK LEAKAGE STUDY
}

(Case Study: Sub Zone 109, Surabaya City)

\author{
Aditya Alden Priangga ${ }^{1}$, Yanto Budisusanto ${ }^{1}$ \\ ${ }^{1}$ Institut Teknologi Sepuluh Nopember \\ email: adityalden@gmail.com
}

\begin{abstract}
Abstrak
Perkembangan ilmu pengetahuan dan teknologi yang pesat menyebabkan perubahan yang besar pada kemajuan perangkat elektronik. Salah satunya adalah perangkat mobile. Saat ini perangkat mobile hampir setara dengan perangkat desktop karena perangkat mobile sudah bisa digunakan hampir seperti penggunaan perangkat desktop. Jika dibandingkan dengan perangkat desktop, perangkat mobile memiliki keunggulan dalam mobilitasnya. Dengan adanya perangkat mobile yang canggih, dapat dibuat sebuah Sistem Informasi Geografis dalam basis mobile yang berguna untuk memecahkan masalah-masalah yang ada di dalam negeri, salah satunya adalah permasalahan kebocoran yang dialami oleh PDAM. Penelitian ini dilakukan di Kota Surabaya, pada jaringan pipa tersier sub-zona 109 yang telah menerapkan DMA. Analisa jaringan pipa menggunakan perangkat lunak EPANET 2.0 yang kemudian dilanjutkan dengan pembuatan Sistem Informasi Geografis berbasis mobile memakai perangkat lunak Eclipse 4.4.2 yang mendukung bahasa Java. Selain itu digunakan juga perangat lunak pendukung yaitu Android Development Tools, serta Google Maps Android API v2 yang digunakan untuk mengakses data - data dari Google Maps. Setelah penelitian ini dilakukan, didapatkan nilai maksimum kecepatan aliran air pada sub zona 109 adalah 1,55 m/s. Lokasi yang berpotensi mengalami kebocoran berada pada daerah di sekitar Jalan Manunggal. Aplikasi SIG berbasis mobile android berhasil dibuat dengan menggunakan bahasa pemrograman Java. Aplikasi ini bernama MGIS29 dengan ukuran 2,93 mb.
\end{abstract}

Kata Kunci: Google Maps, Java, Mobile Android, Sistem Informasi Geografis, Sub Zona 109

\begin{abstract}
The rapid development of science and technology led to large changes in the advancement of electronic devices. One of which is a mobile device. Currently the mobile device is almost equal with desktop devices because mobile devices can be used almost like a desktop device usage. When compared with desktop devices, mobile devices have the advantage of mobility. With the sophisticated mobile devices, a Geographic Information System can be made in the mobile base that is useful to solve the problems that exist in the country, one of which is the problem of leakage experienced by PDAM. This research was carried out at Surabaya City, on sub-zones 109 tertiary pipelines that have DMA implemented. Pipeline analysis using EPANET 2.0 software which is then followed by the manufacture of mobilebased Geographic Information System using Eclipse 4.4.2 software that supports the Java language. Also used support software called Android Development Tools, and Google Maps Android API v2 to access Google Maps data. After the study was conducted, the maximum water flow rate value obtained in the sub zone 109 is $1.55 \mathrm{~m} / \mathrm{s}$. Potential leak locations are in the area around Jalan Manunggal. Android based mobile GIS applications successfully made using the Java programming language. This application is called MGIS29 with a size of $2.93 \mathrm{mb}$.
\end{abstract}

Keywords: Google Maps, Java, Mobile Android, Sistem Informasi Geografis, Sub Zona 109. 


\section{PENDAHULUAN}

\section{Latar Belakang}

PDAM Kota Surabaya merupakan peninggalan jaman Belanda dengan visi menyediakan air minum yang cukup bagi pelanggan melalui perusahaan air minum yang mandiri, berwawasan global, dan terbaik di Indonesia. Pipa - pipa distribusi air milik PDAM pun kebanyakan masih merupakan sisa peninggalan jaman Belanda. Kondisi ini menyebabkan sebuah permasalahan yang dialami oleh hampir seluruh PDAM karena umur pipa yang sudah uzur, yaitu kebocoran. Kebocoran memang merupakan masalah yang umum dihadapi oleh PDAM. Ketua Umum Persatuan Perusahaan Air Minum Indonesia (Perpamsi), Syaiful, mengatakan, kebocoran air pada jaringan distribusi Perusahaan Daerah Air Minum (PDAM) di wilayah perkotaan sampai $33 \%$. "Tingkat kebocoran air PDAM cukup tinggi, non revenue water tiap PDAM rata-rata mencapai 33\%," katanya pada pembukaan lokakarya dan forum bisnis Indonesian-Danish Water Day 2010 di Jakarta (BPPSPAM, 2010). Skala kebocoran ini melebihi batas toleransi 20\% yang ditetapkan Menteri Dalam Negeri lewat Surat Keputusan Nomor 47 Tahun 1999 tentang Pedoman Penilaian Kinerja PDAM. Menurut Direktur Utama PDAM Kota Surabaya, total jaringan pipa PDAM Surabaya mencapai 3.000 kilometer. Saat ini tingkat kebocoran diperkirakan $30 \%$. Pipa PDAM yang sering mengalami kebocoran adalah pipa tersier, pipa ini merupakan pipa dengan diameter dan ketebalan paling kecil dari pipa yang lain (primer dan sekunder) sehingga menyebabkannya rawan bocor.

Sistem Informasi Geografis berbasis mobile menurut Tsou (2004), adalah merupakan sebuah integrasi cara kerja perangkat lunak atau keras untuk pengaksesan data dan layanan geospasial melalui perangkat bergerak via jaringan kabel atau nirkabel. Sistem ini lebih praktis dibandingkan SIG

desktop, karena hanya dibutuhkan sebuah perangkat seluler dan jaringan internet untuk pengoperasaiannya. Aplikasi SIG mobile dapat diintegrasikan dengan Google, sehingga proses penganganan kebocoran dapat dilakukan dengan lebih mudah dikarenakan fitur-fitur pada pengintegrasian dengan Google mendukung fitur navigasi dan penentuan posisi pengguna. Data spasial yang disajikan oleh Google juga lebih baik dibandingkan data spasial pada SIG desktop pada umumnya, dikarenakan data spasial dari Google akan update dengan sendirinya serta tampilannya dapat diubah sesuai kebutuhan pengguna.

\section{Perumusan Masalah}

Berdasarkan latar belakang penelitian di atas, maka rumusan masalah yang akan dibahas sebagai berikut:

1.Bagaimana cara mengidentifikasi lokasi kebocoran?

2.Dimana lokasi yang berpotensi mengalami kebocoran?

3.Langkah apa yang harus dilakukan PDAM guna mengurangi kebocoran?

4.Apa manfaat Sistem Informasi Geografis berbasis mobile android bagi PDAM?

\section{Batasan Masalah}

Pembuatan batasan masalah diperlukan agar penelitian yang dilakukan tidak melebar serta tidak sistematis, dan dengan adanya keterbatasan waktu, maka perlu adanya batasan - batasan tertentu yaitu:

1.Daerah penelitian terbatas pada sub zona 109 yang berada di bagian selatan Kota Surabaya.

2.Analisa jaringan ditinjau dari sisi hidrolisnya saja.

3.Jaringan pipa yang ditinjau adalah jaringan pipa tersier.

4.Analisa jaringan menggunakan program bantu EPANET 2.0.

\section{Tujuan}

Adapun tujuan dalam penelitian ini adalah:

1.Melakukan analisa kecepatan aliran air pada jaringan pipa.

2. Menentukan jaringan pipa yang berpotensi mengalami kebocoran.

3. Membuat SIG jaringan pipa untuk perangkat seluler dengan OS Android.

\section{Manfaat}

Manfaat dari penelitian ini adalah:

1.Menyediakan informasi potensi kebocoran.

2.Membantu mengurangi angka kebocoran yang terjadi pada sub zona yang di teliti. 
3.Sebagai acuan bagi PDAM dalam menentukan kebijakan monitoring guna mencegah kebocoran.

4.Sebagai acuan petugas lapangan dalam melakukan monitoring di lapangan.

\section{METODOLOGI PENELITIAN}

\section{Data Dan Peralatan}

- Data

Data yang digunakan dalam penelitian ini adalah:

1. Data vektor jaringan pipa tersier PDAM Kota Surabaya

2. Data diameter dan panjang pipa serta data elevasi untuk setiap node pada sub zona 109

3. Data pemakaian air pelanggan pada sub zona 109 bulan Januari-April tahun 2015

- Peralatan

Peralatan yang digunakan dalam penelitian ini adalah:

1. Perangkat Keras Laptop Dell N4110

2. Perangkat Lunak EPANET 2.0

3. Perangkat Lunak EpaCAD

4. Perangkat Lunak SIG

5. Perangkat Lunak Eclipse 4.4.2

6. Perangkat Lunak Android Development Tools (ADT)

7. Perangkat Lunak Pengolah Data Tabular

\section{Metode Penelitian}

Lokasi penelitian ini mengambil daerah studi pada sala satu sub zona di Kota Surabaya, yaitu pada sub zona 109 yang berada di wilayah Surabaya Selatan.

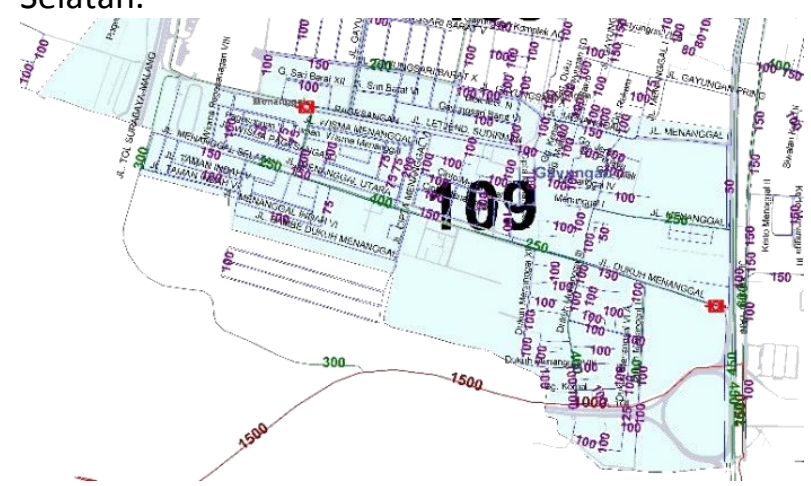

Gambar 1. Lokasi Penelitian (PDAM)

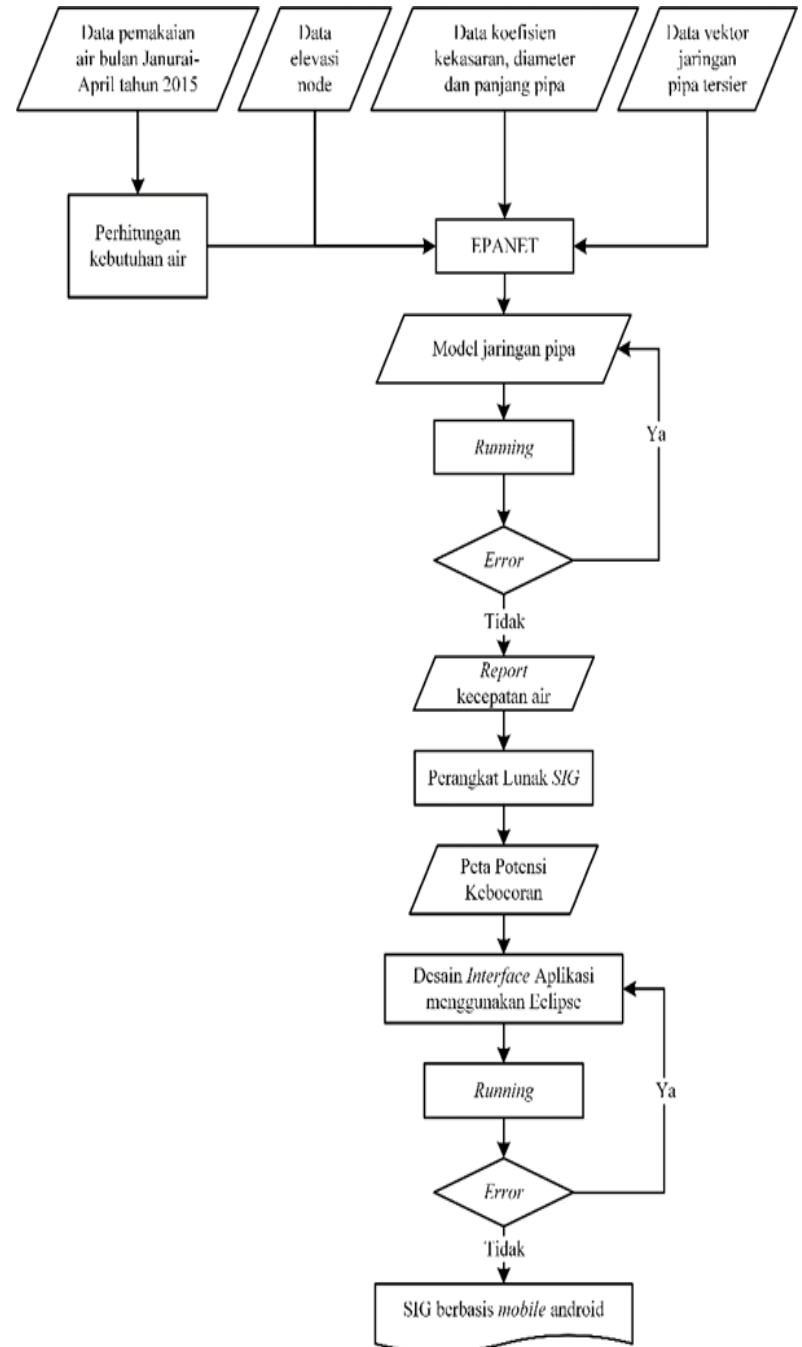

Gambar 2. Diagram Alir Pengolahan Data

Adapun penjelasan diagram alir tahapan pengolahan data sebagai berikut:

a. Tahap pengumpulan data

Data yang dikumpulkan berupa data diameter dan panjang pipa, data elevasi tiap node, data vektor jaringan pipa tersier sub zona 109 dan data pemakaian air bulan Januari-April tahun 2015.

Dengan menggunakan data vektor, dibuat model jaringan pipa tersier yang ada pada sub zona 109 di dalam EPANET 2.0 dengan cara sebagai berikut :

i. Data vektor dengan format shapefile dikonversi menjadi drawing exchange format (.dxf) menggunakan perangkat lunak SIG.

ii. Dengan menggunakan sebuah software bernama EpaCAD, data vektor dalam format .dxf dikonversi menjadi .inp. Data .inp ini adalah data yang digunakan dalam program 
EPANET 2.0 sehingga didapatkan model jaringan pipa yang dibutuhkan.

iii. Didapatkan model jaringan pipa tersier pada sub zona 109.

b. Tahap pengolahan data dan analisa

i. Data vektor di import ke dalam EPANET 2.0 kemudian data elevasi node serta data diameter dan panjang pipa digunakan sebagai atributnya.

ii. Menghitung kebutuhan air minimum menggunakan data pemakaian air tahun 2015 dan hasilnya akan menjadi atribut seperti data di atas. Perhitungan kebutuhan air bersih pada sub zona 109 dilakukan untuk mendapatkan data nilai base demand, nilai ini digunakan sebagai input data pada model jaringan yang ada di dalam program EPANET 2.0.

iii. Data panjang dan diameter akan digunakan sebagai input data untuk pipa, sedangkan data elevasi dan kebutuhan air digunakan untuk input data pada node / junction. Ketiga data dimasukkan melalui property editor seperti pada gambar 2.3, 2.5 dan 2.6. Data yang dimasukkan kedalam EPANET 2.0 harus memiliki satuan yang sama. Satuan di dalam EPANET 2.0 untuk tinggi adalah meter, untuk panjang adalah meter, untuk diameter adalah milimeter, dan untuk kebutuhan air adalah liter/detik. Terdapat lagi data yang dibutuhkan sebagai input dasar dalam program EPANET 2.0 sebelum analisa jaringan dapat dilakukan. Data yang dimaksud adalah data roughness coefficients atau koefisien kekasaran. Data ini digunakan sebagai input untuk pipa. Ada beberapa nilai roughness coefficients yang dapat dimasukkan seperti pada tabel 2.1. Nilai roughness coefficients yang dimasukkan harus sesuai dengan bahan dari pipa itu sendiri serta persamaan head loss apa yang digunakan dalam EPANET 2.0. Data lain yang juga diperlukan adalah pump curve, efficiency curve dan time pattern. Seluruh data yang digunakan sebagai input dalam perangkat lunak EPANET 2.0 berasal dari PDAM Surya Sembada Kota Surabaya.

iv. Tahap selanjutnya adalah running model yang telah dibuat sebelumnya guna mendapatkan hasil analisa jaringan. v. Hasil running pertama pasti menimbulkan error, model jaringan harus dikoreksi sesuai dengan error yang muncul sampai hasil running sukses dan didapatkan report kecepatan air.

vi. Proses selanjutnya dilanjutkan di dalam perangkat lunak SIG untuk melakukan proses pembuatan peta potensi kebocoran.

vii. Kemudian membuat code untuk membangun SIG berbasis mobile android sesuai dengan tujuan penelitian menggunakan perangkat lunak Eclipse 4.4.2 dan perangkat lunak pendukung berupa ADT serta Google Maps Android API v2.

\section{c. Tahap hasil}

Apabila running program pada Eclipse telah sukses tanpa mengalami error, maka aplikasi yang dibuat sudah selesai dan file dengan ekstensi .apk dapat di install pada mobile device.

\section{HASIL DAN PEMBAHASAN}

\section{Hasil Perhitungan Kebutuhan Air}

Tabel 1. Pemakaian Air Rata - Rata Pelanggan Periode Januari-April 2015

\begin{tabular}{|c|c|c|c|c|}
\hline \multirow{2}{*}{ No. } & \multirow{2}{*}{ SUB_ZONA } & \multirow{2}{*}{ JALAN } & \multirow{2}{*}{$\begin{array}{c}\text { PELANGGAN } \\
\text { SR } \\
\end{array}$} & \multirow{2}{*}{$\begin{array}{c}\text { PEMAKAIAN } \\
\mathrm{m}^{3} / \mathrm{bln} \\
\end{array}$} \\
\hline & & & & \\
\hline 1 & 109 & A. YANI & 32 & 1,773 \\
\hline \multirow[t]{2}{*}{2} & 109 & CIPTA & 545 & 9,381 \\
\hline & & MENANGGAL & & \\
\hline \multirow[t]{2}{*}{3} & 109 & DUKUH & 300 & 4,311 \\
\hline & & MENANGGAL & & \\
\hline 4 & 109 & GAYUNGAN & 92 & 4,050 \\
\hline \multirow[t]{2}{*}{5} & 109 & LETJEN & 3 & 107 \\
\hline & & SUDIRMAN & & \\
\hline 6 & 109 & MENAGGAL & 1,432 & 44,653 \\
\hline 7 & 109 & PAGESANGAN & 313 & 5,828 \\
\hline \multirow[t]{2}{*}{8} & 109 & PAGESANGAN & 18 & 475 \\
\hline & & AGUNG & & \\
\hline \multirow[t]{2}{*}{9} & 109 & PAGESANGAN & 7 & 40 \\
\hline & & KEHUTANAN & & \\
\hline \multirow[t]{2}{*}{10} & 109 & PAGESANGAN & 4 & 59 \\
\hline & & TIMUR & & \\
\hline \multirow[t]{2}{*}{11} & 109 & PAGESANGAN & 146 & 3,920 \\
\hline & & WISMA & & \\
\hline 12 & 109 & TAMAN INDAH & 155 & 3,692 \\
\hline \multirow[t]{4}{*}{13} & 109 & WISMA & 228 & 6,148 \\
\hline & & BUNGURASIH & & \\
\hline & JUM & & 3,275 & 93,000 \\
\hline & PEMAKAIAN & TA-RATA & $28,4 \mathrm{~m}^{3} / \mathrm{bln}$ & \\
\hline
\end{tabular}

Data di atas didapatkan dari PDAM Kota Surabaya sudah dalam bentuk rata - rata 4 bulan. Data pemakaian air digunakan untuk melakukan perhitungan kebutuhan air (base demand) yang akan digunakan sebagai input dalam perangkat lunak EPANET 2.0.

Proses perhitungan kebutuhan air dimulai dengan merubah satuan nilai jumlah pakai asli dalam 
$\mathrm{m} 3 / \mathrm{bln}$ menjadi satuan It/s dengan cara nilai awal dikali 1000 kemudian dibagi dengan 2592000. Didapatkan nilai $35,88 \mathrm{lt} / \mathrm{s}$ yang merupakan nilai total dari base demand. Nilai pemakaian rata rata juga diubah ke dalam satuan $\mathrm{It} / \mathrm{s}$ dan didapatkan nilai 0,011 It/s. Nilai 0,011 It/s merupakan nilai base demand yang akan di sebar ke junction-junction

yang berada di dalam jaringan pipa. Dari hasil diskusi dengan PDAM Kota Surabaya, didapatkan jumlah sebaran junction tersebut yaitu 52 junction.

Seluruh nilai base demand harus terdistribusi di dalam jaringan pipa agar pada saat proses analisa dijalankan kondisi model jaringan pipa pada perangkat lunak EPANET 2.0 mendekati kondisi di lapangan. Maka nilai total base demand dikurangkan dengan perkalian nilai 0,011 dengan banyaknya junction sebelumnya yaitu 52 , didapatkan nilai 35,31 It/s. nilai tersebut merupakan nilai base demand yang belum terdistribusi ke dalam jaringan. Dari hasil diskusi dengan PDAM Kota Surabaya, nilai 35,31 It/s dibulatkan menjadi 35 dan akan didistribusikan ke dalam 35 junction.

\section{Hasil Pengolahan EPANET}

Data yang didapat dari tahap pengumpulan data dapat dilihat pada bagian lampiran. Data ini didapat dari PDAM Kota Surabaya. Setelah proses pengumpulan data dan input data selesai, dilakukan analisa pada model jaringan pipa dengan cara memilih menu run analysis pada EPANET 2.0. Apabila hasil run analysis masih belum success dilakukan pengecekan pada model jaringan pipa beserta atribut-atributnya sampai hasil run analysis success. Selanjutnya menampilkan report dari hasil run analysis. Output report yang ditampilkan hanya nilai kecepatan seperti gambar 3. Report ini digunakan sebagai dasar dalam melakukan analisa potensi kebocoran.

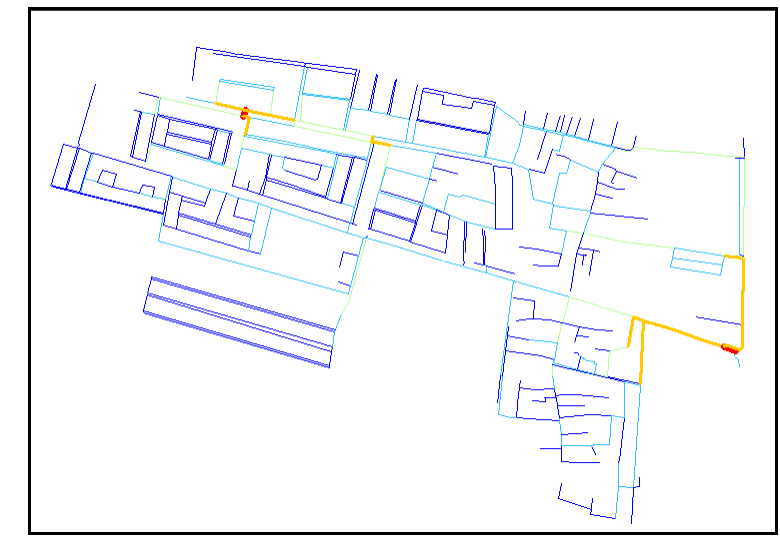

Gambar 3. Hasil Velocity Report Pipa

\section{Hasil Pengolahan SIG}

Dari hasil velocity report atau laporan kecepatan pada pipa, kecepatan yang tinggi kebanyakan berada di dekat lokasi sumber air dari jaringan pipa tersebut, hal ini diakibatkan oleh perubahan diameter pipa dari sumber air menuju saluran distribusi. Hasil report tersebut diekspor kedalam format .shp sehingga dapat diolah di dalam perangkat lunak SIG. Terlihat pada gambar $3 \mathrm{di}$ atas, hasil laporan kecepatan dibagi menjadi 5 secara otomatis oleh perangkat lunak EPANET 2.0. Tabel 2. Klasifikasi Kecepatan Air

\begin{tabular}{cc}
\hline Kategori & Nilai $(\mathrm{m} / \mathrm{s})$ \\
\hline Rendah & $<0,8$ \\
Normal & $0,8-1,2$ \\
Tinggi & $>1,2$ \\
\hline
\end{tabular}

Pada perangkat lunak SIG, akan dikategorikan secara manual menjadi 3 kategori dengan berdasarkan pada tabel 2 di atas. Untuk kecepatan antara 0,8-1,2 m/s akan masuk kategori normal, nilai kecepatan di bawah normal $(<0,8)$ akan masuk kategori rendah sedangkan di atas normal $(>1,2)$ akan masuk kategori tinggi.

\section{SIG Berbasis Mobile Android}

Hasil akhir dari penelitian berupa SIG berbasis mobile android dalam bentuk aplikasi dengan ekstensi .apk yang dapat di install pada mobile device. Aplikasi ini dapat digunakan pada mobile device dengan OS Android antara Ice Cream Sandwich (Android 4.0) sampai dengan yang terbaru yaitu Lollipop (Android 5.0). Aplikasi ini bernama MGIS29. Pada aplikasi MGIS29 terdapat beberapa fitur yang dapat digunakan oleh user guna mempermudah pemakaian aplikasi, yaitu : 
a. Fitur Lokasi

Fitur ini dapat diakses menggunakan tombol - pada aplikasi. Fungsi dari fitur ini adalah untuk mentarget posisi user saait itu agar berada di tengah - tengah layar. Fitur ini juga berguna untuk menampilkan posisi user saat itu di dalam aplikasi dengan titik biru.

Fitur ini diaktifkan menggunakan kode di bawah ini pada bagian yang di blok. Untuk kode yang tidak di blok digunakan untuk menampilkan peta Google Maps pada aplikasi.

b. Fitur Orientasi dan Legenda

Fitur ini berguna untuk menampilkan arah utara, fitur ini akan aktif apabila user merotasi tampilan Google Maps. Tidak dibutuhkan kode untuk mengaktifkan fitur ini.

Untuk fitur legenda dapat ditampilkan menggunakan kode seperti di bawah

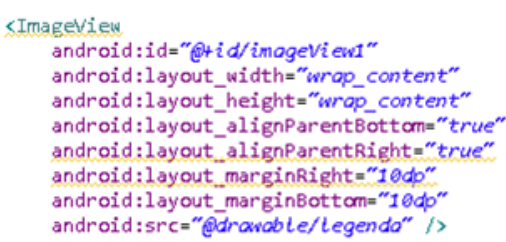

Gambar 4. Kode untuk menampilkan Legenda

\section{c. Fitur Zoom}

Fitur ini berguna untuk merubah tingkat zoom dari aplikasi agar sesuai dengan keinginan user. Fitur ini dapat diakses menggunakan gesture 2 jari. Fitur ini secara otomatis aktif tanpa harus menambahkan kode untuk mengaktifkannya.

d. Fitur Tampilan

Apabila user ingin merubah tampilan dari Google Maps, dapat digunakan fitur ini. Fitur ini dibagi menjadi 2, yang pertama adalah untuk merubah tampilan Google Maps menjadi normal dengan mengunakan tombol NORMAL Fitur ke dua adalah untuk merubah tampilan Google Maps menjadi hybrid dengan menggunakan tombol

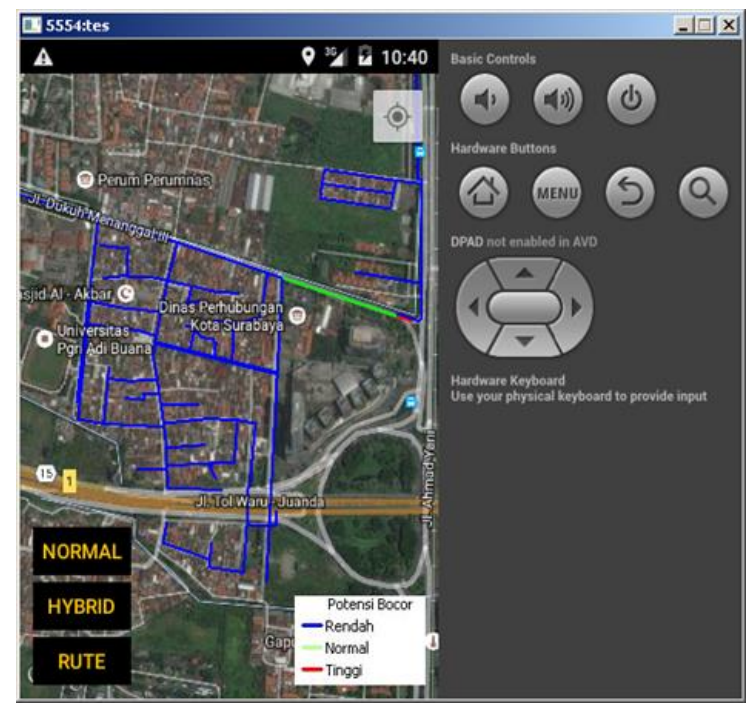

Gambar 5. Tampilan Aplikasi dalam mode Hybrid

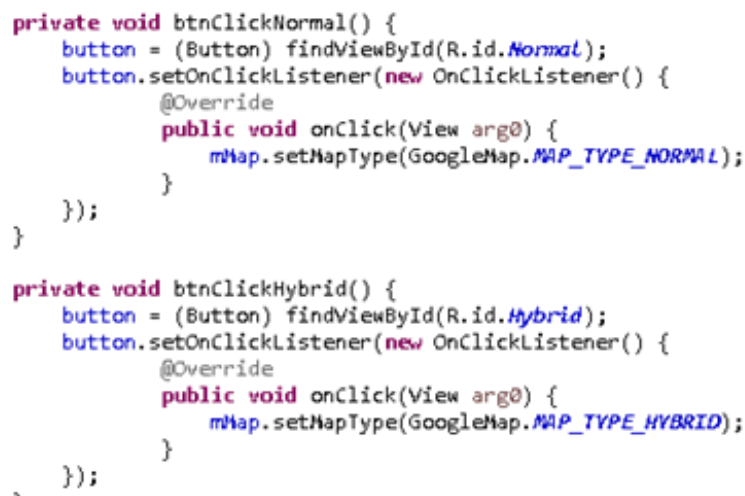

Dengan menggunakan kode di atas, fitur tampilan dapat diaktifkan pada aplikasi.

e. Fitur Rute

Merupakan fitur yang dapat digunakan untuk membuat rute pada aplikasi dari posisi user menuju lokasi yang diinginkan. Fitur ini dapat diakses menggunakan tombol RUTE dengan terlebih dahulu menentukan lokasi yang akan dituju. Untuk menentukan lokasi yang dituju, user melakukan gesture touch and hold sampai

muncul marker pada aplikasi.

Fitur rute merupakan fitur yang membutuhkan aplikasi lain agar dapat digunakan. Pada mobile device yang digunakan oleh user harus terdapat aplikasi Maps (Google Maps Android). Fitur ini ditampilkan menggunakan kode seperti di bawah ini. 


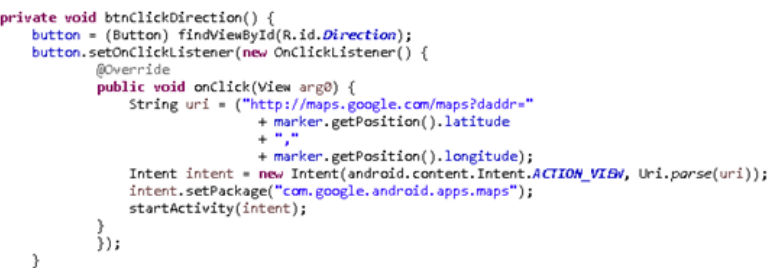

Gambar 7. Kode untuk Fitur Rute

\section{Analisa Kebutuhan Air}

Berdasarkan tabel 1, jumlah pelanggan terbanyak berada pada Jalan Menanggal dengan jumlah sambungan rumah sebanyak 1.432 . Pemakain air per bulan pada daerah ini juga merupakan yang tertinggi, dengan nilai $44.653 \mathrm{~m} 3 / \mathrm{bln}$. Kebutuhan air setiap pelanggan berbeda-beda, tidak selalu jumlah pelanggan sedikit maka pemakaiannya juga sedikit, begitu juga sebaliknya. Hal ini ditunjukkan dengan nilai pemakaian air terendah terdapat pada Jalan Pagesangan Kehutanan dengan nilai $40 \mathrm{~m} 3 / \mathrm{bln}$ dan jumlah sambungan rumah sebanyak 7 . Sedangkan jumlah pelanggan terendah terdapat pada Jalan Letjen Sudirman dengan hanya 3 sambungan rumah dan nilai pemakaian air sebanyak 107 m3/bln.

\section{Analisa Jaringan Pipa}

Analisa ini berdasarkan hasil pengolahan data dengan perangkat lunak EPANET. Terlihat pada hasil report pada gambar 3 , pipa dengan nilai kecepatan air tertinggi (antara 0,94-1,55 m/s) yang ditunjukkan dengan warna merah terletak pada pipa-pipa yang tersambung langsung dengan sumber air. Hal ini disebabkan oleh diameter antara pipa distribusi dengan pipa sumber air berbeda, sehingga menyebabkan perubahan tekanan yang dapat menyebabkan kecepatan aliran air yang tinggi. Pipa-pipa yang berada di sekitar pipa dengan kecepatan yang tinggi juga mengalami kecepatan yang tinggi, kecepatannya berkisar antara 0,47-0,94 m/s ditunjukkan dengan warna kuning.

\section{Analisa Kecepatan Air}

Dari hasil diskusi dengan PDAM Kota Surabaya, nilai kecepatan aliran air berbanding lurus dengan potensi kebocoran. Sehingga potensi kebocoran ditentukan berdasarkan nila kecepatan aliran air pada jaringan pipa distribusi. Semakin tinggi kecepatan maka potensi kebocoran juga semakin tinggi. Hasil potensi kebocoran berupa peta potensi kebocoran.

\section{Analisa Uji Aplikasi}

Aplikasi dujikan pada mobile device Samsung Galaxy Young Duos dengan OS Android Jelly Bean. Pengujian aplikasi yang dilakukan yaitu :

a. Uji Interface

Pengujian ini bertujuan untuk mengetahui apakah aplikasi dapat dijalankan pada mobile device yang sesungguhnya. Sehingga dari uji tampilan ini dapat diketahui apabila semua fungsi untuk menyampaikan informasi yang dimiliki oleh aplikasi dapat berjalan dengan baik.

b. Uji Penentuan Posisi Pada saat aplikasi pertama kali di buka dan titik biru yang menandakan lokasi user muncul maka penentuan posisi telah berhasil.

c. Uji Pembuatan Rute

Setelah marker lokasi yang ingin dituju ditambahkan, tombol rute ditekan dan beberapa detik kemudian muncul jendela baru yang menunjukkan pilihan - pilihan rute dari posisi user menuju lokasi yang diinginkan. Saat salah satu rute dipiilih, maka rute akan terplot secara otomatis pada aplikasi.

d. Uji Perubahan Tampilan

Tampilan dari Google Maps dapat berubah sesuai dengan tombol yang ditekan. Untuk tampilan Google Maps Normal dapat dilihat pada Gambar di bawah, sedangkan untuk tampilan Google Maps dalam mode Hybrid seperti Gambar 5.

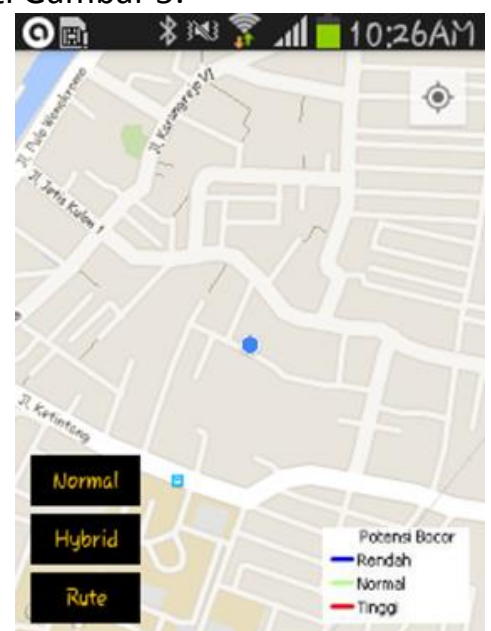

Gambar 8. Tampilan Aplikasi dalam Mode Normal 
e. Uji Penyampaian Informasi

Uji ini ditekankan kepada kemampuan aplikasi dalam menyampaikan informasi spasial. Pengujian ini dilakukan dengan cara membandingkan hasil dari input dari 2 buah aplikasi, yang pertama adalah aplikasi MGIS29 dan yang ke 2 adalah aplikasi Google Maps yang diakses menggunakan laptop. Nilai koordinat yang akan diujikan terdapat pada tabel 3 di bawah.

Tabel 3. Nilai Koordinat

\begin{tabular}{ccc}
\hline No & Lintang & Bujur \\
\hline 1 & $-7,295794$ & 112,736472 \\
2 & $-7,299388$ & 112,746260 \\
3 & $-7,279261$ & 112,790433 \\
\hline
\end{tabular}

Dari pengujian terhadap ke 3 koordinat, ke 2 aplikasi menunjukkan hasil lokasi yang sama. Penyampaian informasi yang ditampilkan oleh MGIS29 telah sesuai dengan aplikasi Google Maps yang di akses menggunakan laptop.

Dari hasil beberapa uji aplikasi yang telah dilakukan, diperoleh beberapa kelebihan dan kekurangan dari aplikasi SIG berbasis mobile android ini, yaitu :

a. Kelebihan dari aplikasi :

i. Dapat memberikan informasi lokasi user di dalam aplikasi.

ii. Dapat menentukan rute perjalan dari lokasi user menuju lokasi yang diinginkan.

iii. Aplikasi dapat memberikan 2 tampilan Google Maps untuk memenui kebutuhan user.

iv. Terdapat fitur - fitur tambahan seperti fitur arah orientasi, legenda dan lokasi.

v. Aplikasi dapat dijalankan pada perangkat telepon seluler, sehingga dapat digunakan oleh petugas lapangan PDAM.

b. Kekurangan dari aplikasi :

i. Aplikasi ini hanya menyajikan informasi pada sub-zona 109.

ii. Untuk menampilkan peta Google Maps memerlukan akses internet.

iii. Proses penentuan rute user memerlukan akses internet.

\section{PENUTUP}

\section{Kesimpulan}

Berdasarkan hasil penelitian yang telah dilakukan, didapat kesimpulan sebagai berikut :

1. Nilai maksimum kecepatan aliran air dalam pipa dari hasil analisa jaringan adalah 1,55 m/s.

2.Lokasi yang berpotensi mengalami kebocoran menurut hasil analisa jaringan pada pipa berada di sekitar sumber air yang masuk dalam jaringan pipa sub zona 109, tepatnya di daerah Jalan Manunggal.

3.Pembuatan aplikasi SIG jaringan pipa untuk perangkat seluler dengan OS Android berhasil dibuat, aplikasi ini bernama MGIS29 dengan ukuran 2,93 mb. Proses pembuatannya menggunakan bahasa pemrograman Java.

\section{Saran}

Saran untuk PDAM Surya Sembada Kota Surabaya sebagai berikut :

1.Melakukan penelitian lanjutan agar aplikasi dapat diterapkan pada sub-zona yang lain dengan menambahkan fitur update database.

2.Mengembangkan aplikasi agar memiliki fitur simpan posisi serta menampilkan koordinat dari posisi tersebut.

3. Melakukan pengembangan lebih lanjut agar aplikasi SIG berbasis mobile dapat bekerja tanpa mnggunakan akses jaringan internet (offline mode).

\section{UCAPAN TERIMAKASIH}

Penulis A.A.P. mengucapkan terima kasih kepada PDAM Surya Sembada Kota Surabaya selaku instansi yang telah memberikan data guna mendukung dalam keberhasilan penelitian ini.

\section{DAFTAR PUSTAKA}

Ardiansyah, H. 2014. Modul Sistem Distribusi. Surabaya: PDAM Surya Sembada Kota Surabaya.

Arifianto, T. 2011. Membuat Interface Aplikasi Android Lebih Keren dengan LWIT. Yogyakarta: Penerbit Andi.

Aronoff, S. 1989. Geographic Information Systems: a management perspective. Ottawa: WDL Publications. 
Berry, K. 2000. GIS Technology in Environmental Management. Colorado USA.

BPPSPAM. 2010. Kebocoran Air PDAM Capai 33\%. <URL:http://bppspam.com/index.php?opti on=com_content $\&$ view=article $\& i d=343: k e$ bocoran-air-pdam-capai-33\&catid=3 4:bam>. Dikunjungi pada tanggal 25 Juni 2015, jam 05.30.

Burrough, P. 1986. Principle of Geographical Information System for Land Resources Assesment. Oxford: Claredon Press.

Chang, K.T. 2002. Introduction to geographic information systems, Volume 1. Idaho: McGraw-Hill.

Chrisman, N.R. 1999. What does 'GIS'mean?. USA: Department of Geography, University of Washington.

Harmon, John E., Anderson, Steven J. 2003. The Design and Implementation of Geographic Information Systems. Canada: John Wiley \& Sons, Inc.

Herlin, Rr.Y. 2013. Pemanfaatan SIG Untuk Monitoring Kebocoran Jaringan Pipa PDAM Di Kabupaten Demak. Semarang: Undip.

Hermawan, S.S. 2011. Mudah Membuat Aplikasi Android. Yogyakarta: Penerbit Andi.

Hussein, Asmaa Ahmed., Eibrahim, Elkhedr Hassan., Asem, Aziza. 2011. Mobile Geographic Information Systems: a Case Study on Mansoura University Egypt. International Journal of Computer Science \& Information Technology (IJCSIT), Vol 3 No 6, pp 173-181.

J. Morrison, S. Tooms, D. Rogers. 2007. District metered areas guidance notes. Int. Water Assoc. (IWA), Water Loss Task Force.

Kadir, A. 2005. Dasar pemrograman Java 2. Yogyakarta: Penerbit Andi.

PDAM. 2015. PDAM Surya Sembada Kota Surabaya <URL: $\quad$ http://www.pdam-sby.go.id>.
Dikunjungi pada tanggal 9 Juli 2015, jam 21.40.

Prihandito, Aryono. 1989. Kartografi. Yogyakarta: PT. Mitra Gama Widya.

Raisz, Erwin. 1948. General Cartography. New York: Mc. Graw Hill Book Co. Inc.

Rickyanto, I. 2005. Dasar Pemrograman Berorientasi Objek Dengan Java 2 (JDK 1.4) edisi 2. Yogyakarta: Penerbit Andi.

Riyanto. 2010. Sistem Informasi Geografis berbasis Mobile. Yogyakarta: Penerbit Gava Media.

Rossman, L.A. 2000. EPANET 2 Users Manual. National Risk Management Research Laboratory. Cincinnati: U.S. Enviromental Protection Agency.

Safaat, H.N. 2011. Android : Pemrograman Aplikasi Mobile Smartphone dan Tablet PC. Bandung: Penerbit Informatika.

Sharma, Ritik., Garg, Shubhangi., Kumar, Yogesh., Mutreja, Jeevash. 2013. Developing An Application For M-GIS To Access Geoserver Through Mobile For Importing Shapefile. International Journal of Engineering Research \& Technology (IJERT), Vol. 2 Issue 4, pp 2690-2698.

Sutrisno, H. 2010. Aplikasi SIG Dengan ArcView 3.3 Untuk Simulasi Perancangan Pipa Di PDAM Tirta Moedal Kota Semarang Sub Zona Bukit Sari. Semarang: Undip.

Tsou, Ming-Hsiang. 2004. Integrated Mobile GIS and Wireless Internet Map Servers for Environmental Monitoring and Management. Cartography and Geographic Information Science, Vol. 31 No. 3, pp. 153-165.

Yuwono. 2000. Kartografi Dasar. Surabaya: Program Studi Teknik Geodesi FTSP-ITS. 